\title{
Land-use planning risk estimates for a chemical industrial park in China - A longitudinal study
}

Hu, Xinsheng; Wu, Zongzhi; Hedlund, Frank Huess; Pedersen, Jan Boier; Wang, Rujun; Duo, Yingquan; Sin, Gürkan

Published in:

Process Safety Progress

Link to article, DOI:

10.1002/prs.11972

Publication date:

2018

Document Version

Peer reviewed version

Link back to DTU Orbit

Citation (APA):

Hu, X., Wu, Z., Hedlund, F. H., Pedersen, J. B., Wang, R., Duo, Y., \& Sin, G. (2018). Land-use planning risk estimates for a chemical industrial park in China - A longitudinal study. Process Safety Progress, 37(2), 124-133. https://doi.org/10.1002/prs.11972

\section{General rights}

Copyright and moral rights for the publications made accessible in the public portal are retained by the authors and/or other copyright owners and it is a condition of accessing publications that users recognise and abide by the legal requirements associated with these rights.

- Users may download and print one copy of any publication from the public portal for the purpose of private study or research.

- You may not further distribute the material or use it for any profit-making activity or commercial gain

- You may freely distribute the URL identifying the publication in the public portal 


\title{
Land-use planning risk estimates for a chemical industrial park in China - a longitudinal study
}

Xinsheng $\mathrm{Hu}^{1}$, Zongzhi $\mathrm{Wu}^{1,2}$, Frank Huess Hedlund ${ }^{3,4}$, Jan Boier Pedersen ${ }^{3}$, Rujun Wang ${ }^{5,6}$, Yingquan Duo $^{5,6}$, Gürkan Sin ${ }^{7}$

1 Faculty of Resource and Safety Engineering, China University of Mining and Technology (Beijing), Beijing, 100083, China

2 The Occupational Safety and Health Administration, State Administration of Work Safety, Beijing, 100713, China

3 COWI, Kongens Lyngby, DK-2800, Denmark

4 Technical University of Denmark (DTU/Compute) Kongens Lyngby, DK-2800, Denmark

5 Institute of safety technology for hazardous chemicals, China Academy of Safety Science and Technology, Beijing, 100012, China

6 Key Laboratory of Major Hazard control and Accident Emergency Technology, State Administration of Work Safety, Beijing, 100012, China

7 PROSYS research center, Department of Chemical and Biochemical Engineering, Technical University of Denmark, Kongens Lyngby, DK-2800, Denmark

\begin{abstract}
A chemical industrial park (CIP) can centralize the management of companies and facilitate mutual communication between different businesses. Due to these advantages, an increasing number of chemical companies are forced into CIP, especially in developing countries such as China. Thus, the land-use planning of CIP associated with safety becomes an important issue. To illustrate the importance of the continuous risk supervision and give more experiences to other similar changing CIP, we apply a simplified quantitative risk assessment procedure to estimate the risk to a Chinese chemical industrial park $(19 \times 10 \mathrm{~km} 2)$ near a rather densely populated off-site region for the years 2014 and 2017. Estimated levels of individual risk and societal risk are compared with Chinese risk acceptance criteria for landuse planning. Off-site risk levels have increased significantly from 2014 to 2017. While off-site risk levels are still low and within the acceptable region, the study concludes that the authorities should review carefully and monitor the risk level in case of future development activities around and within the chemical industrial park, e.g. preserving a buffer zone should be considered. For future chemical park design, it is highly recommended to proactively include QRA analysis especially to deal with risk in an efficient way.
\end{abstract}

Keywords: chemical industrial park, major hazard potential, quantitative risk assessment, risk acceptance criteria, land-use planning 


\section{Introduction}

Chemical industrial parks (CIP) centralize chemical companies such as production, storage, refineries, etc., which can save cost and facilitate unified management. Examples exist in Jurong Island, Singapore; Tarragona, Spain; Antwerp, Belgium; BASF Ludwigshafen, CHEMPARK Leverkusen, among many in Germany; Bahia Blanca, Argentina among others. Usually CIP enhances exploitation of synergistic potential and benefits between upstream and downstream industrial activities in view of material supply, product processing, and transportation. In order to maximize the function of CIP, it is rational to optimize the layout of the park, which is the aim of the land-use planning. Land-use planning usually considers economic, operational and safety aspects. Due to large amount of the hazardous chemicals inventory in the CIP, potential safety risk becomes an important priority in land use planning decisions. To ensure proper safety, quantitative risk assessment (QRA) studies are typically used, which plays a key role for the decision maker to permit or deny a project. Pasman and Reniers anticipated that more countries will use QRA to support land-use planning [1]. Khan and Abbasi have estimated the overall individual risk of a chemical cluster near residential areas[2]. The result shows that the risk level did not meet the criteria. Baesi, et al. used QRA to evaluate the risk impact of a new chemical plant on an existing one in an industrial region [3]. Their result indicated that the new plant did not have a major impact on the risk levels, however, the societal risk had a significant increase. Several other relevant studies can be found elsewhere ([4][5] [6][7][8][9]).

To ensure proper safety of a CIP, a continuous regulatory oversight e.g. for the plant construction permitting is necessary, especially when new projects or companies enter the park that will increase the overall risk level. This issue is particularly important in developing country such as China. By 2013, about 30\% of the chemical companies were built in or relocated to CIPs, which is influenced by the government policy [10]. Although China's economy has expanded tremendously, especially the growth of the gross industrial product of the petroleum and chemical industry with an annual average rate of $25 \%$, industrial accidents have become a major threat to health and environment in China [11], such as Tianjin Port explosion [12][13] in 2015 that led to 165 deaths and Nanjing explosion [14] in 2010 that killed 22 people and led to the evacuation of thousands of residents. To reduce chemical disasters, China has improved chemical accident prevention strategies and issued land-use planning regulations [15]. Therefore, as a policy response, China has actively promoted re-location of industrial sites to Chemical Industrial Parks (CIP).

The dynamic nature of a CIP (changing inventory levels and chemical industrial activities) leads to a changing risk level, which means the risk influences of the nearby public area are different at the different time. However, none of the above mentioned studies focused on risk estimates for land-use planning near chemical industrial parks and how such risk estimates change over time. The present paper contributes to fill this gap.

Therefore, this study focuses on performing a systematic examination of off-site risk levels for a greenfield chemical industrial park in the context of land use planning which remains an important contemporary societal and economic challenge. The scope of the study is set to examine the off-site risk assessment of chemical parks to nearby densely populated areas using a retrospective case study to analyze safety issues arising from chemical industrial park activities. To this end, the paper applies a simplified QRA approach to estimate the risk to the nearby off-site areas for the years 2014 and 2017. 


\section{Material and methods}

\section{Chinese chemical industrial park overview}

In the northern part of China, the government reserved a greenfield area of $19 \times 10 \mathrm{~km}^{2}$ for a Chemical Industrial Park (CIP). In 2014, four companies were operating. By the end of 2016, an additional eight were operating, bringing the total to 12 companies. Off-site populated areas are located to the western side of the park, comprising e.g. multi-storey apartment blocks, shops, light industry, and agricultural land. From the maps, it does not appear that a distinct buffer zone is planned to separate populated areas and the CIP. The northern, southern and eastern sides of the chemical industrial park face water bodies, unsuitable for residential development. A sketch of the chemical park layout is shown in Figure 1, while the companies operating in the park are listed in Table 1.

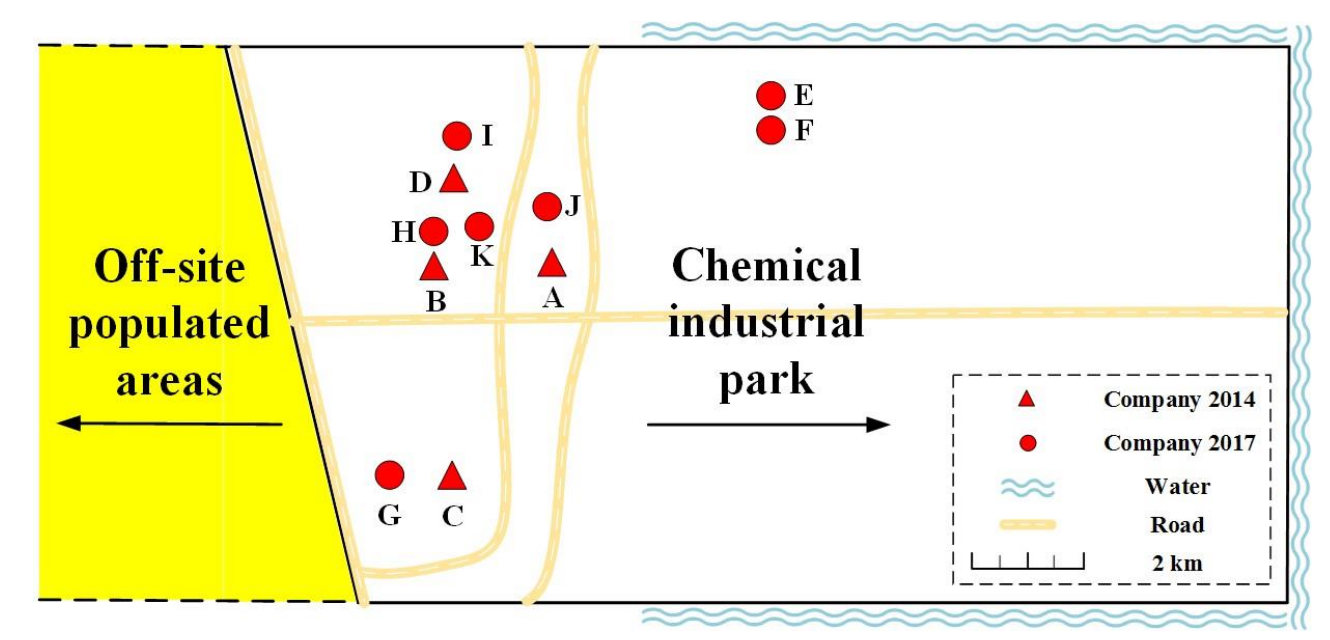

Figure $1 \quad$ Layout of $19 \times 10 \mathrm{~km}^{2}$ CIP and companies in 2014 and 2017. The study estimates risk levels for the off-site populated areas.

Table 1 The 12 companies operating Jan. 1, 2017.

\begin{tabular}{clc}
\hline Name & \multicolumn{1}{c}{ Profile } & $\begin{array}{c}\text { In operation } \\
\text { (year) }\end{array}$ \\
\hline A & Crude oil storage & 2014 \\
B & Crude oil storage & 2014 \\
C & Polyacrylamide production & 2014 \\
D & Water purifying agent production & 2014 \\
E & Oil and chemicals storage & 2017 \\
F & Petrochemical storage & 2017 \\
G & Oil and gas processing and storage & 2017 \\
H & Refined products storage & 2017 \\
I & Refined products storage & 2017 \\
J & Crude oil storage & 2017 \\
K & Fine chemicals (benzoic acid) production & 2017 \\
L & Gas storage (not shown) & 2017 \\
\hline
\end{tabular}




\section{Simplified QRA approach}

Currently, most companies listed in Table 1 are located kilometers from the nearest populated areas, the nearest being at distance $500 \mathrm{~m}$. The considerable separation distance allows a simplified approach for off-site risk estimation, which is adopted in this study. This is consistent with the purpose of the QRA in this study- estimating off-site risk to nearby populated areas. Therefore, we consider only the scenarios that have the largest releases of the most hazardous substances that can potentially affect the off-site populated areas.

Based on a brief review of major past accidents, we identify the major hazard potential at the CIP and we develop corresponding event trees for the simplified QRA procedure. As will be argued later, the off-site risk influenced only by major releases of LPG and volatile liquids such as gasoline, crude oil and toxic gases such as acrylonitrile. Relevant consequences are heat radiation from BLEVEs and flash fires, blast effects from Vapor Cloud Explosion (VCE) and dispersion of toxic gas.

Figure 2 shows the simplified QRA approach. First, we select the major hazard potential based on the major past accidents. Second, we collect the input data for each major hazard scenario. Third, we estimate the risk of each major scenario using the software Phast Risk. Finally, we analyze the risk estimates and compare them against risk acceptance criteria in China and make necessary recommendations.

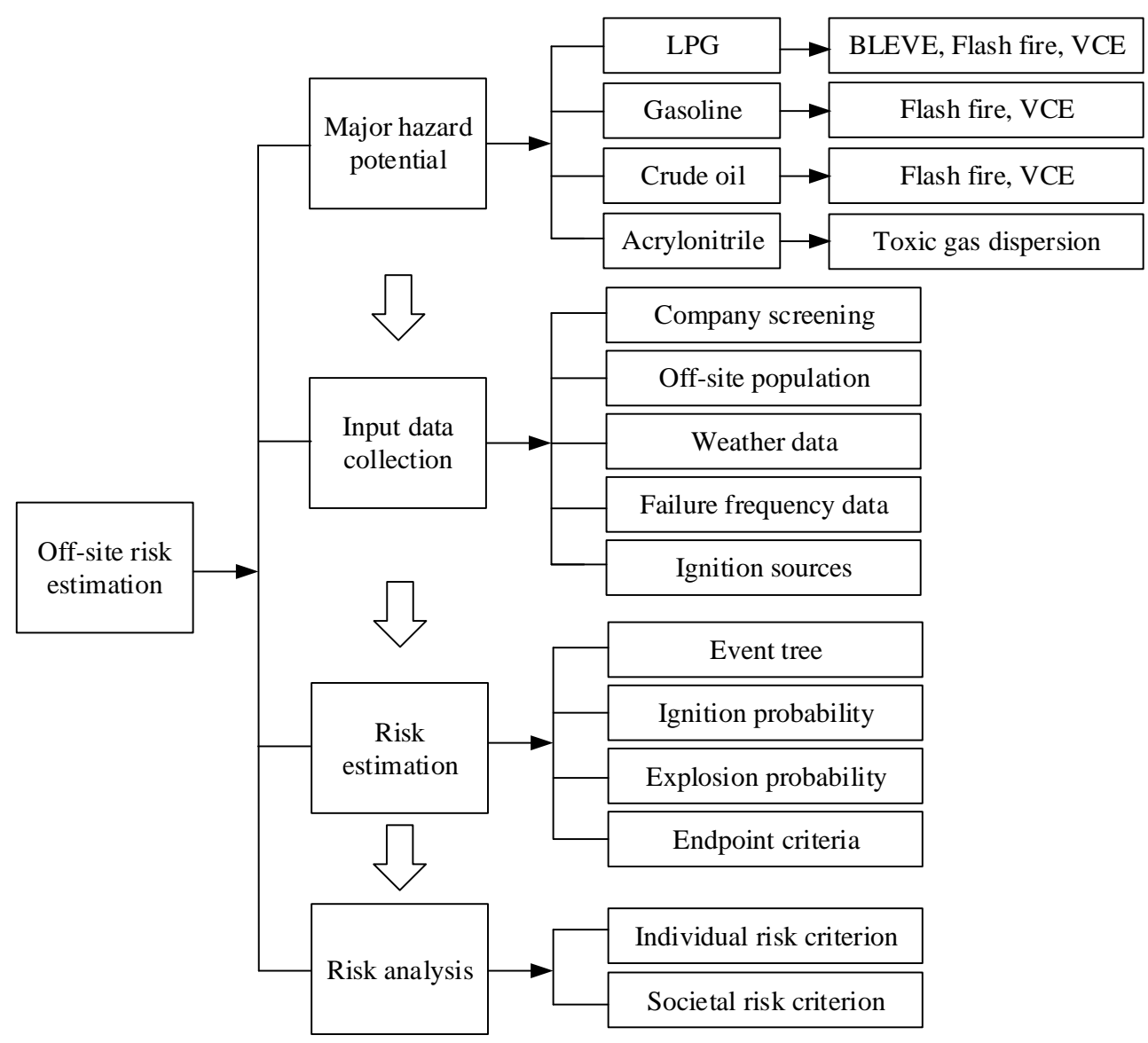

Figure 2 The simplified QRA approach used in this study. 


\section{Brief review of major past accidents}

\section{Major hazard potential of LPG}

LPG, -short for Liquefied Petroleum Gas- are kept in pressure vessels at ambient temperature. BLEVE, vapor cloud explosion and flash fire are the three major hazard potential of LPG leak. Two typical past accidents associated with LPG leak is reviewed briefly as follows:

(a) On 4 January 1966, water draining procedure went wrong resulting in a leak of propane sphere at Feyzin, France [16]. Vapors drifted downwind and then were ignited by a car on a public road about 150 $\mathrm{m}$ away. The flame travelled back to the sphere (flash fire) and burned as a torch fire. The torch weakened the pressure vessel, which failed due to BLEVE (escalation) that gave rise to a large fireball, which killed 18 people and injured 81 more. The blast damaged nearby LPG tanks, which after some time also failed due to ensuing BLEVE event.

(b) Another similar accident occurred on 19 November 1984, at the PEMEX LPG storage site near Mexico City [17]. An LPG vessel overfilled, vapors drifted downwind for more than $400 \mathrm{~m}$, reaching a shantytown where it found a source of ignition. The resulting flash fire killed many people there. The flame travelled back to the point of release and after some time the vessel failed due to ensuing BLEVE event (escalation). The blast damaged nearby LPG tanks, which after some time also failed in several other BLEVEs. The intense heat radiation from the fireballs led to many additional fatalities.

For our case study here, we conclude that a small leak, if ignited, can lead to a BLEVE with large consequences. Large leaks, if ignited late, may produce large vapor clouds which can drift for considerable distance before they ignite leading to a flash fire or a vapor cloud explosion. This scenario is described in the event tree shown in Error! Reference source not found..

\section{Major hazard potential of gasoline}

Gasoline is a flammable liquid, stored in pressure-less tanks at ambient temperature. Vapor cloud explosion and flash fire are the two major hazard potential of gasoline overfilling. Two typical past accidents are briefly reviewed as follows:

(a) A gasoline tank overfilling took place in Naples, Italy, on 21 December 1985 [18]. Gasoline overflowed for about 1.5 hours and produced a vapor cloud of about $4500 \mathrm{~m}^{3}$. The vapor cloud drifted in a terrain consisting of tanks and building (congestion) and a high embankment (confinement), which was then ignited and led to a vapor cloud explosion. The blast wave reached up to $5 \mathrm{~km}$ away. Five people died and 170 people were injured in this accident.

(b) Another accident took place in the Buncefield oil storage depot, UK, on 11 December 2005 [19][20]. A gasoline tank overfilled and vapors drifted for more than $200 \mathrm{~m}$. The vapors were ignited late (delayed ignition). The congestion in vapor dispersion due to houses and the bushes caused acceleration of the flame propagation velocity. As a result, a vapor cloud explosion took place leading to a wide scale destruction.

As regards our case study, we conclude that major releases of gasoline can produce clouds that cover large areas. If ignited late, they may led to vapor cloud explosion or flash fire. This potential event is described in the event tree in Error! Reference source not found.. 


\section{Major hazard potential of crude oil}

Crude oil is also a flammable liquid, stored in pressure-less tanks at ambient temperature. Similar to gasoline, vapor cloud explosion and flash fire are the two major hazard potential of crude oil overfilling.

Crude oil presents an additional risk of boilover [21]. For example, a major boilover accident of crude oil happened in Milford Haven, UK, on 30 August 1983 [22]. A boilover, however, only takes place after prolonged burning, such as 1/2-1 day, which offers plenty of time to evacuate people out of harm's way. Therefore, we do not consider boilover as relevant major hazard potential of crude oil for off-site risk in our case study.

\section{Major hazard potential of acrylonitrile}

Acrylonitrile is a volatile flammable and toxic liquid stored in pressure-less tanks at ambient temperature. If released, toxic vapors are emitted. On 20 January 1990, an acrylonitrile leak accident happened in Lima, Ohio, USA [23]. A process tank leak during the reaction of polymerization. The evaporation of acrylonitrile produced toxic and flammable vapors.

Preliminary consequence analysis and calculations showed that toxicity effects have far longer reach than flammable effects. Therefore, consistent with the main purpose of QRA of our study, we only considered toxic gas dispersion as the major hazard potential for off-site risk. This event is described in the event tree in Error! Reference source not found.

\section{Chinese risk acceptance criteria}

Decree No. 13 specify both the individual and the societal risks acceptance criteria for land-use planning [24] which are provided in Table 2 and Figure 3, respectively.

For individual risk, Decree No. 13 specifies acceptance criteria for three types of vulnerable objects (Table 2).

For societal risk acceptance criterion, Decree No. 13 specifies the upper and the lower bounds on the F$\mathrm{N}$ curve (Figure 3). A slope of -1 of the F-N curves represents an accident size-neutral acceptance criteria [25][26].

Table $2 \quad$ Chinese individual risk acceptance criteria.

Individual risk acceptance crite-

No.

Vulnerable object

1 a. Low-density areas (Light industry, vehicle repair shops, etc.);

2 a. Residential high-density areas

(Residential areas, multi-storey apartment blocks, hotels and resorts, etc.);

b. Public high-density areas (Office buildings, shopping malls and entertainments, etc.); 
No.

Vulnerable object

Individual risk acceptance criteria

( fatality risk per year)

3 a. Sensitive objects $\leq 3 \times 10^{-6}$

(Schools, hospitals, kindergartens and nursing homes, etc.);

b. Important objects

(Government departments and military administrations,

etc.);

c. Special high-density areas

(Large stadiums and large transport hub stations, etc.).

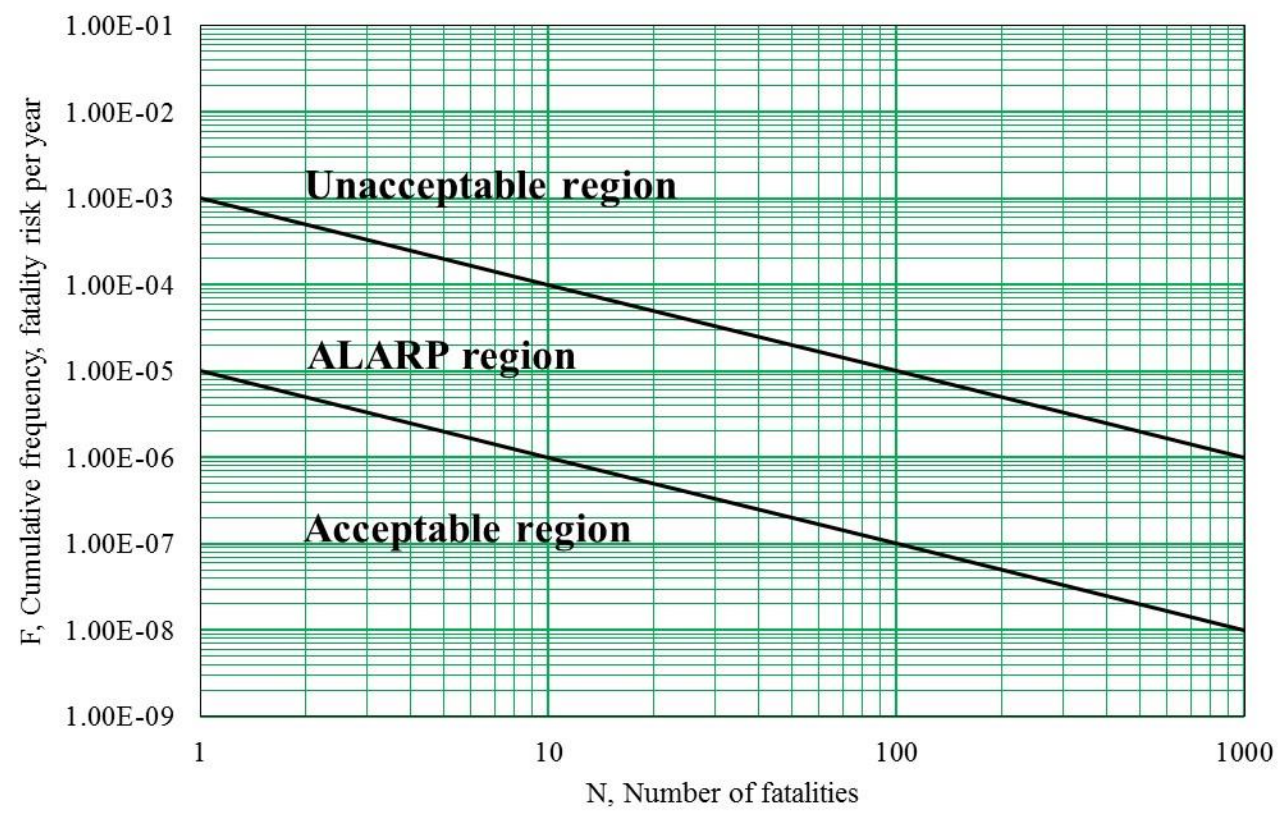

Figure 3 Chinese societal risk acceptance criteria.

\section{Software}

In this study, risks are estimated using Phast Risk (Version 6.705) from DNV GL software. 


\section{Data collection to QRA}

\section{Inventory data collection and company screening}

We have used the following two exclusion criteria for screening out companies for inventory data collection: 1) those companies that are located more than $5 \mathrm{~km}$ away from the off-site areas. This is considered extremely unlikely to affect the off-site risk, and 2) those companies that store diesel and other non-volatile petrochemicals. They are considered extremely unlikely to affect remote off-site areas.

Using these screening criteria, the remaining companies, which potentially could contribute to off-site risk, are shown in Table 3. In general, the storage conditions are ambient pressure and temperature, except for LPG which is stored at approximately $10 \mathrm{barg}$ and the ambient temperature. The location of these companies and their distance to the selected populated areas (numbers in circles) are shown in Figure 4. The figure also details the location of surrounding roads, as vehicles are recognized sources of ignition.

Table $3 \quad$ Companies and their hazardous chemicals with potential for off-site risk.

\begin{tabular}{cccc}
\hline Company & Substance & $\begin{array}{c}\text { Typical tank volume } \\
\left(\mathrm{m}^{3}\right)\end{array}$ & Number of tanks \\
\hline A & Crude oil & 100,000 & 32 \\
\hline B & Crude oil & 100,000 & 10 \\
\hline C & Acrylonitrile & 500 & 3 \\
\hline \multirow{2}{*}{ G } & Crude oil & 5,000 & 4 \\
& LPG & 650 & 5 \\
\hline \multirow{2}{*}{ H } & Gasoline & 20,000 & 2 \\
& Gasoline & 10,000 & 4 \\
\hline \multirow{2}{*}{ I } & Gasoline & 6,000 & 3 \\
& Gasoline & 2,000 & 4 \\
& Gasoline & 2,500 & 2 \\
\hline J & Crude oil & 100,000 & 32 \\
\hline
\end{tabular}




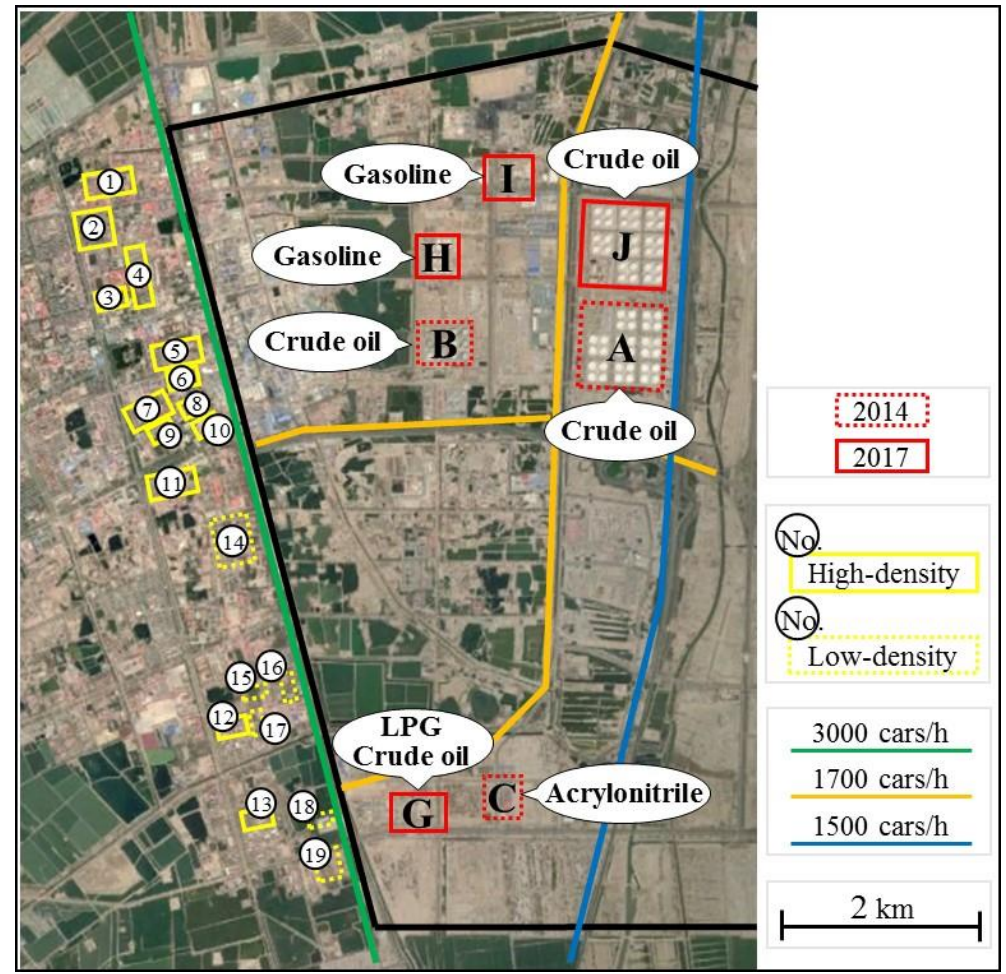

Figure $4 \quad$ Location of companies which potentially could contribute to off-site risk, densely and sparsely populated areas which could potentially be affected, and major roads.

\section{Off-site population}

Because analysis of satellite imagery 2014/2017 provided by Google show insignificant housing change we simply assume the population of 2014 and 2017 are unchanged. Figure 4 shows the extent of highdensity and the low-density populated areas. The Chinese National Standard on Code of Urban Residential Areas Planning and Design specifies per capita living area should be no less than $20 \mathrm{~m}^{2}$ for the multistorey apartment blocks[27], which equals 50,000 people $/ \mathrm{km}^{2}$. Thus, the high-density of 60,000 peo$\mathrm{ple} / \mathrm{km}^{2}$ is conservative. Table 4 lists the specific population data. The total number of the population marked on the map is about 70,000 people.

Table $4 \quad$ Off-site population.

\begin{tabular}{cccc}
\hline Area $^{\text {a }}$ & Density & Type $^{\text {c }}$ & Population \\
\hline 1 & High & Residential (2a.) & 5,000 \\
2 & High & Residential (2a.) & 10,000 \\
3 & High & Residential (2a.) & 5,000 \\
4 & High & Residential (2a.) & 10,000 \\
5 & High & Residential (2a.) & 10,000 \\
6 & High & Residential (2a.) & 3,000 \\
7 & High & Residential (2a.) & 10,000 \\
8 & High & Residential (2a.) & 1,000 \\
9 & High & Residential (2a.) & 1,000 \\
10 & High & Residential (2a.) & 1,000 \\
11 & High & Residential (2a.) & 7,000
\end{tabular}




\begin{tabular}{cccc}
\hline Area $^{\text {a }}$ & Density $^{\text {b }}$ & Type $^{c}$ & Population \\
\hline 12 & High & Residential (2a.) & 3,000 \\
13 & High & Residential (2a.) & 3000 \\
14 & Low & Light industry (1a.) & $<200$ \\
15 & Low & Light industry (1a.) & $<30$ \\
16 & Low & Light industry (1a.) & $<20$ \\
17 & Low & Light industry (1a.) & $<30$ \\
18 & Low & Light industry (1a.) & $<20$ \\
19 & Low & Light industry (1a.) & $<30$ \\
\hline Total & - & - & About 70,000
\end{tabular}

${ }^{\mathrm{a}}$ Area is circled in Figure 4

${ }^{\mathrm{b}}$ Population density per square $\mathrm{km}$, high is about 60,000 , low is about 500 .

${ }^{\mathrm{c}}$ See Table 2 for classification of vulnerable object.

\section{Weather data}

Weather data are shown in Table 5. To simplify the calculations and in alignment with the purpose of the QRA in this study, stability class A/B/C type weathers are treated as stability class D as the latter weather type is more unfavorable to atmospheric dispersion and dilution. We choose representative wind speed 2 $\mathrm{m} / \mathrm{s}$ for F type weather and $2 \mathrm{~m} / \mathrm{s}, 6 \mathrm{~m} / \mathrm{s}, 10 \mathrm{~m} / \mathrm{s}$ for D weather. Based on the local weather statistics available to us, the distribution of weather classes is taken as $35 \% \mathrm{~F}$ and $65 \% \mathrm{D}$. We observe, the occurrence of the very stable F class is considerably larger than what is usual for e.g. Western Europe. The representative weather conditions are applied to 16 wind directions, showing in Figure 5.

Table $5 \quad$ Weather data used in the study, Pasquill atmospheric stability class, and representative wind speed categories and probability of occurrence.

\begin{tabular}{ccc}
\hline Stability class & Wind speed $(\mathrm{m} / \mathrm{s})$ & Percentage $(\%)$ \\
\hline F & 2 & 35 \\
D & 2 & 40 \\
D & 6 & 16.5 \\
D & 10 & 8.5 \\
\hline Total & - & 100 \\
\hline
\end{tabular}




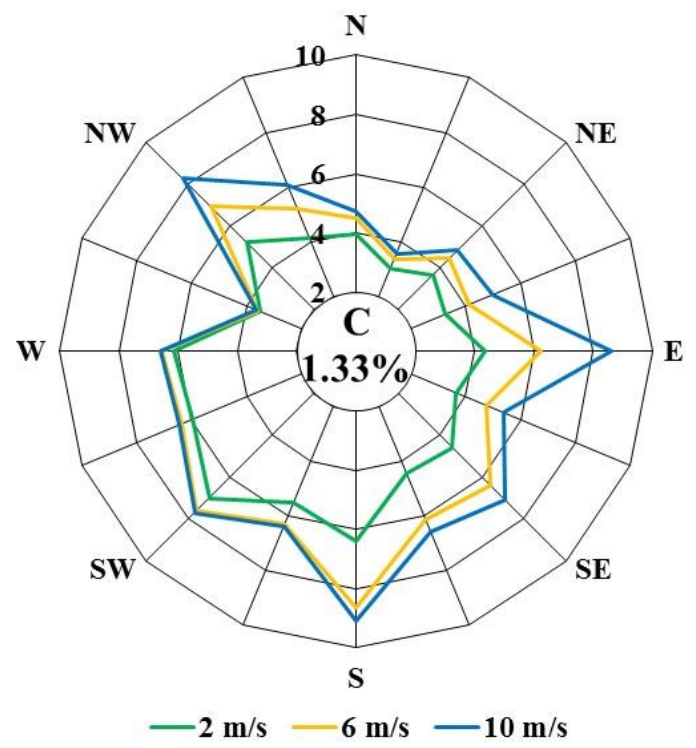

Figure $5 \quad$ Wind rose data show low wind speeds occur often and the lack of a predominant wind direction. Calm weather is indicated as $C$.

\section{Failure frequency data}

The Chinese guidance document [28] specifies standard frequencies that are used as reference frequency data in this case study, shown in Table 6.

Table $6 \quad$ Failure frequency of tank

\begin{tabular}{cccc}
\hline Type & Small and medium leak & Large leak & Rupture \\
\hline Leak aperture & $\varnothing=5 \sim 50 \mathrm{~mm}$ & $\emptyset=50 \sim 150 \mathrm{~mm}$ & $\emptyset>150 \mathrm{~mm}$ \\
\hline $\begin{array}{c}\text { Frequency } \\
\text { (/year/tank) }\end{array}$ & $1.4 \times 10^{-4}$ & $1 \times 10^{-5}$ & $6 \times 10^{-6}$ \\
\hline
\end{tabular}

\section{Ignition sources and probability}

The primary ignition sources around the CIP are assumed to be traffic and the activities of the general population. Ignition time and probabilities are modelled from the standard values in Phast Risk and data for traffic and the population. Figure 4 shows three different traffic flows: (a) The red road connects the CIP to the nearby populated areas, with the highest traffic flow of $3000 \mathrm{cars} / \mathrm{h}$. (b) The yellow roads are the inner traffic paths of the CIP, with the traffic flow of $1700 \mathrm{cars} / \mathrm{h}$. (c) The blue road is the highway connecting to other districts of the city, with the lowest traffic flow of $1500 \mathrm{cars} / \mathrm{h}$. The distribution of the population can be found in Figure 4 and Table 4. 
The ignition probabilities are defined according to the leak sizes. For the small and medium leak, the ignition probability of 0.3 is assigned conservatively[3]. For the large leak and rupture, the delayed ignition probability is calculated by Phast Risk, using standards parameters, traffic flow and the population data (refer to Figure 4).

\section{Explosion probability}

Based on characteristics (congestion etc.) of the terrain affected we have specified a conservative probability of 0.4 for a flash fire to escalate to a vapor cloud explosion[3]. Besides, an area with trees and an elevated road are defined as a congestion and a confinement to model the vapor cloud explosion.

\section{Endpoint criteria}

Endpoint criteria define the boundary of the consequence calculation leading to fatal harm.

(a) For BLEVE, fatality risk is calculated by Phast Risk using a standard probit function shown in (Eq 1):

$P_{r}=-36.38+2.56 \ln \left(Q^{4 / 3} \times t\right)$

where, Pr is the probit corresponding to the probability of death $(-), \mathrm{Q}$ is the heat radiation $\left(\mathrm{W} / \mathrm{m}^{2}\right), \mathrm{t}$ is the exposure time (s).

(b) For vapor cloud explosion, an overpressure of $0.01 \mathrm{MPa}$ is assumed to correspond to $1 \%$ lethality. This is based on the definition in the guidance document [28] that the death probability of people is 0 when the overpressure is smaller than $0.01 \mathrm{MPa}$. On the contrary, $0.03 \mathrm{MPa}$ is assumed to correspond to $100 \%$ lethality.

(c) For flash fire, the distance to 0.5 Lower Flammable Limit (LFL) is used as the endpoint. The fatality risk for people inside and outside the envelope of $0.5 \mathrm{LFL}$ is considered to be $100 \%$ and $0 \%$, respectively.

(d) For toxic gas dispersion, fatality risk is calculated by the probit function for acrylonitrile shown in (Eq 2):

$P_{r}=-7.52+\ln \left(C^{1.3} \times t\right)$

where, Pr is the probit corresponding to the probability of death (-), $\mathrm{C}$ is the concentration (ppm), $\mathrm{t}$ is the exposure time (min). 


\section{Results and discussion}

\section{Event tree formulation for potential major accidents LPG event tree}

Error! Reference source not found. shows the potential event trees of LPG leak associated with a small and medium gas leak versus a large leak and a rupture of tank.

A small leak, if ignited, can lead to a BLEVE with large consequences. This is important because small leaks are more frequent than large leaks. Large leaks and ruptures, if ignited late, may produce large vapor clouds which can drift for considerable distance before they ignite leading to a flash fire or a vapor cloud explosion. We ignore the BLEVE contribution to risk resulting from a large leak or a rupture, partly because the consequence of the flash fire is larger, and secondly because the BLEVE is already included in the small leak event scenario, which contributes to risk with a higher frequency. We ignore further escalation to later BLEVEs in neighboring tanks because we select the tank with the largest volume for the calculations and fatalities are counted already in the first BLEVE.

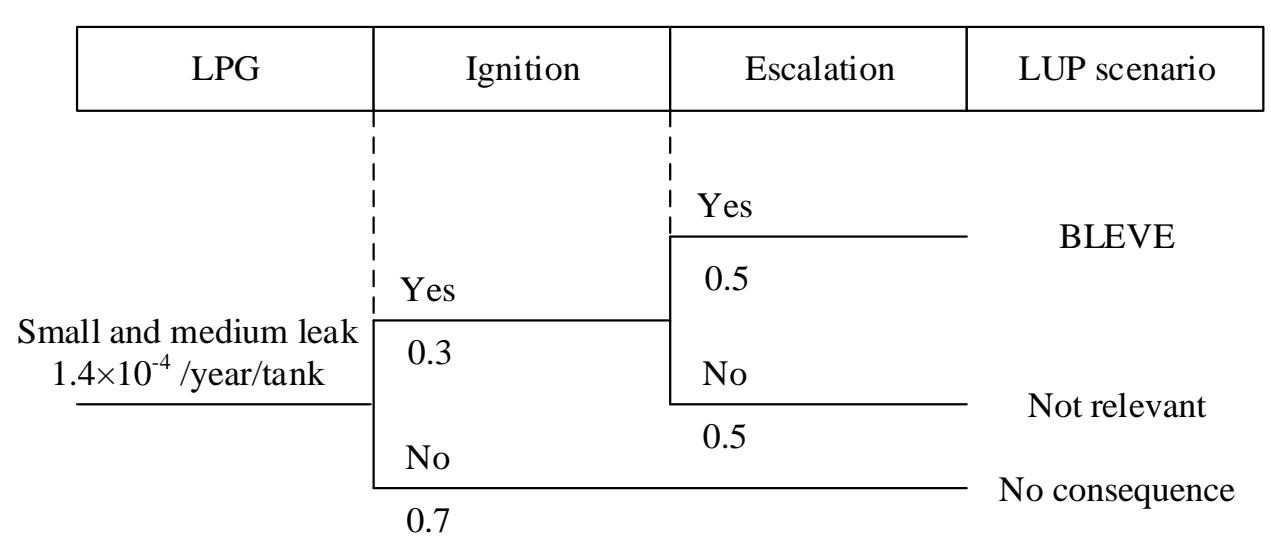

(A)

\begin{tabular}{|c|c|c|c|}
\hline LPG & Delayed ignition & Explosion & LUP scenario \\
\hline \multirow{3}{*}{$\begin{array}{c}\text { Large leak } \\
1 \times 10^{-5} / \text { year } / \text { tank } \\
\text { or } \\
\text { Rupture } \\
6 \times 10^{-6} / \text { year } / \operatorname{tank}\end{array}$} & \multirow[b]{2}{*}{ Yes } & Yes & \multirow{3}{*}{ VCE } \\
\hline & & 0.4 & \\
\hline & \multirow[b]{2}{*}{ No } & No & \\
\hline & & 0.6 & Flash fire \\
\hline
\end{tabular}

(B)

Figure $6 \quad$ Event trees of $L P G$ with small and medium leak (A), large leak or rupture (B). 
The event tree shows that small and medium leak may result in a BLEVE, no matter if the ignition occurs early on or at a later stage after the leak. For large leak and rupture, only delayed ignition leads to consequences of interest, i.e. vapor cloud explosion or flash fire. We simply specify conservative probabilities of ignition, escalation and explosion. Initiating frequencies for small and medium leaks combined, large leak, and rupture are taken from Chinese guidance document [28].

\section{Gasoline event tree}

Error! Reference source not found. shows the event tree of gasoline storage units. The major off-site hazard potential of gasoline is related to very large releases with delayed ignition, which may lead to vapor cloud explosion or flash fire. Due to recent accidents (e.g. Buncefield), large releases due to overfilling are key concerns. Transfer frequencies and flow rates, which are required to consider overfill scenarios, are not available to this study. Therefore we consider only large leaks and ruptures. We consider this approach conservative as earlier work by COWI (unpublished) concluded that ruptures produce larger vapor clouds than overfill events, and because improved overfill protection measures as a result of recommendations following the recent overfilling related accidents have reduced the frequency to the extent that the frequency contribution from ruptures may become equally or more important [29].

\begin{tabular}{|c|c|c|c|}
\hline Gasoline & Delayed ignition & Explosion & LUP scenario \\
\hline \multirow{3}{*}{$\begin{array}{c}\text { Large leak } \\
1 \times 10^{-5} / \text { year/tank } \\
\text { or } \\
\text { Rupture } \\
6 \times 10^{-6} / \text { year/tank }\end{array}$} & & Yes & \multirow{3}{*}{ VCE } \\
\hline & Yes & \multirow[t]{2}{*}{0.4} & \\
\hline & \multirow[b]{2}{*}{ No } & & \\
\hline & & 0.6 & Flash fire \\
\hline
\end{tabular}

Figure $7 \quad$ Event tree of gasoline with large leak or rupture.

\section{Crude oil event tree}

The estimation procedure for crude oil is similar to gasoline. The consequence analysis results are found to be less severe however, as crude oil is assumed to be less volatile than gasoline.

\section{Acrylonitrile event tree}

Error! Reference source not found. shows the event tree of acrylonitrile storage. A major release, evaporation and dispersion of toxic vapors is found as the major hazard potential of acrylonitrile. We conservatively assume that no releases ignite, i.e. all major releases produce vapor clouds so that we compute an upper bound of the risk estimate for this event also consistent with above scenarios. 


\begin{tabular}{|c|c|c|}
\hline Acrylonitrile & Ignition & LUP scenario \\
\hline $\begin{array}{c}\text { Large leak } \\
1 \times 10^{-5} / \text { year/tank } \\
\text { or } \\
\text { Rupture } \\
6 \times 10^{-6} / \text { year/tank }\end{array}$ & 1 & \\
& No & \\
& Yes & Noxic gas dispersion \\
& 0 & Not relevant
\end{tabular}

Figure $8 \quad$ Event tree of acrylonitrile with large leak or rupture.

\section{Upper estimates for risk}

In accordance with Chinese guidance document [28], the study considers spontaneous cold rupture of large storage vessels and instantaneous releases of very large quantities of hazardous materials. Although similar approaches are used in other guidelines [30]we note that the resulting risk estimates obtained in our study are conservative, i.e. they are upper estimates for the actual risk levels. Other assumptions applied in the study also give conservative estimates, for instance the simplified treatment of weather data. This approach taken is sensible for a crude estimation of off-site risk level.

The estimated risk within the CIP itself may not be conservative, however, as we have screened out certain contributors to risk. They are not applicable to near-field, only the far-field, i.e. off-site populated areas. In summary, the actual risk values presented below should be viewed with caution and interpreted within the scope and specific aim of this study.

\section{Individual risk}

Figure 9 shows the off-site individual risk from the CIP in 2014 and 2017, respectively. Three risk contours of red, yellow and green represent the risk levels of $3 \times 10^{-5}, 1 \times 10^{-5}$ and $3 \times 10^{-6}$ death/year, which correspond to the limits set in the Decree No. 13 [24].

In 2014, the overall off-site risk of CIP evidently does not exceed any of the criteria. In 2017, results indicate that the most stringent criteria may be exceeded near the boundary of the low-density areas. The stringent criteria are not applicable to those areas, however, as it is low-density. Hence, no criteria are violated. 


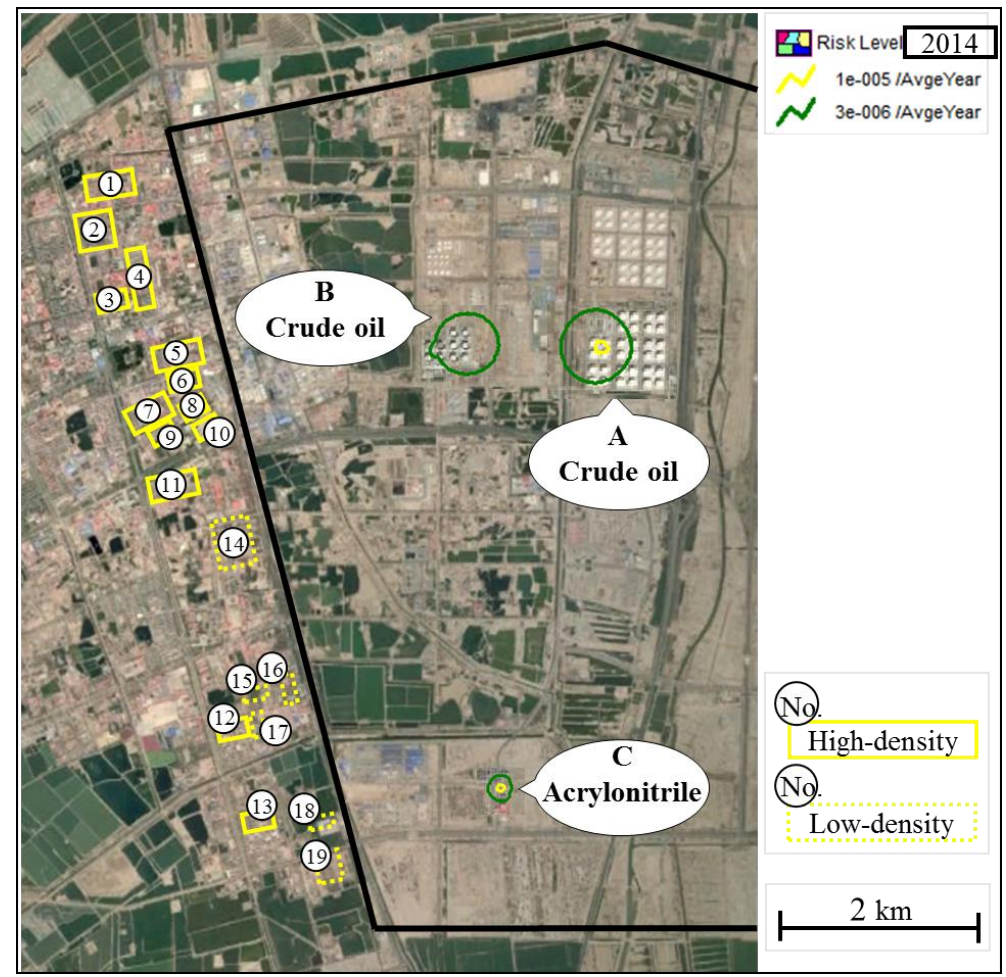

(A)

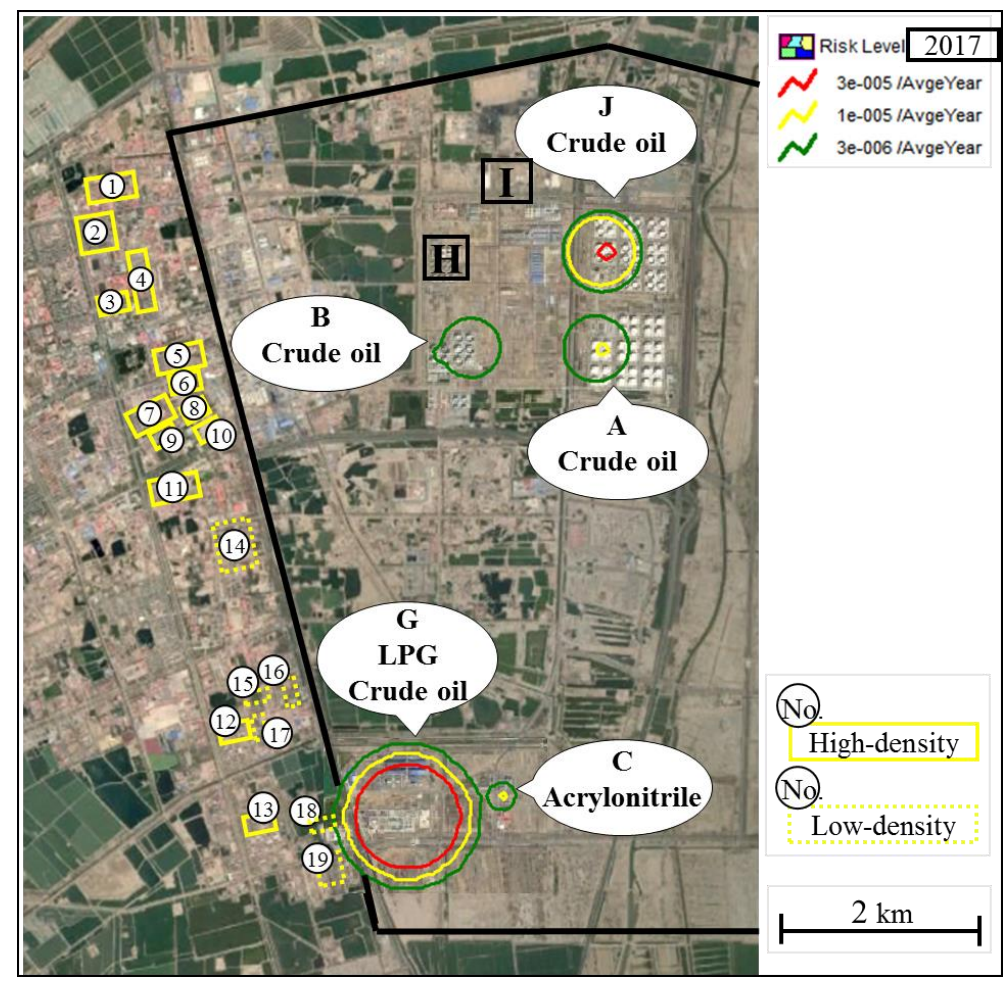

(B)

Figure $9 \quad$ Individual risk contours in 2014 (A) and 2017 (B). 


\section{Societal risk}

Figure 10 shows the off-site societal risk from CIP in 2017. In 2014, off-site societal risk is so low that the F-N curve cannot be estimated. In 2017, off-site risks have increased and the F-N curve can be estimated. Risk levels are low and in the acceptable region.

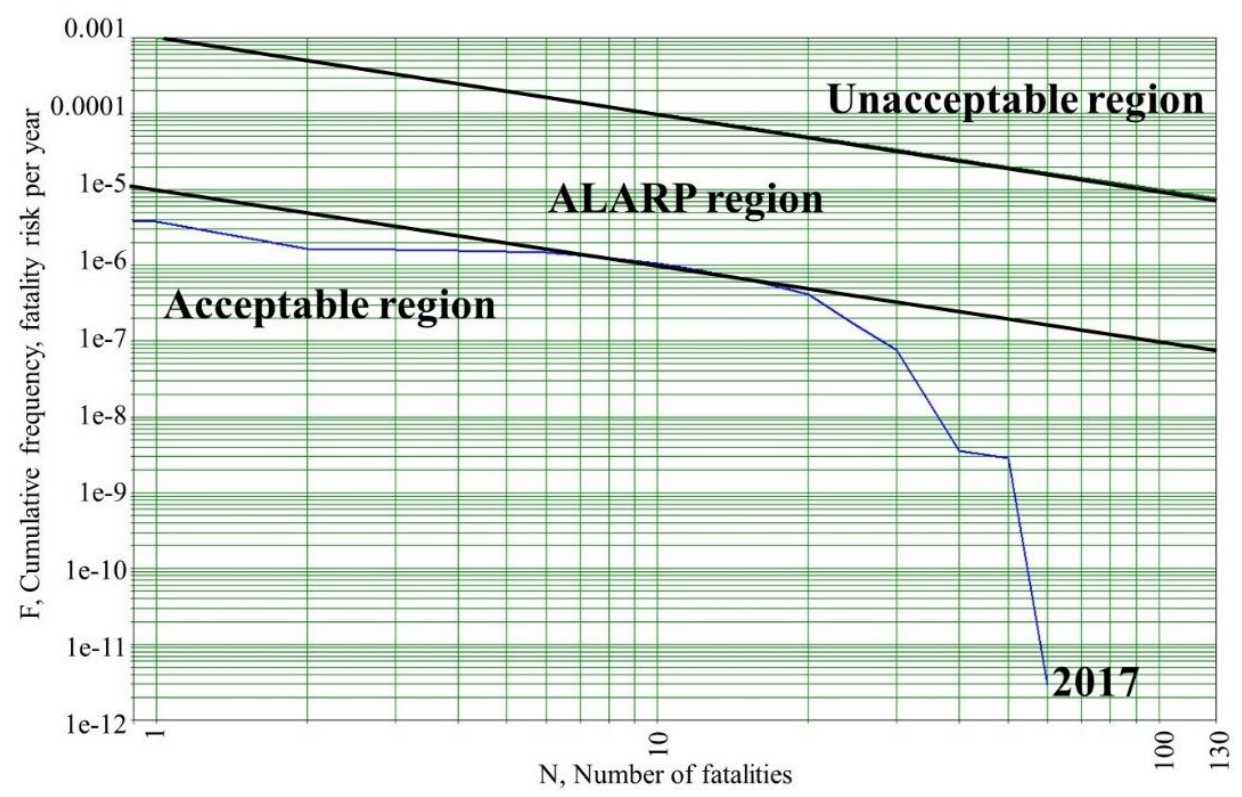

Figure $10 \quad$ Societal risk curves in 2017 (risks in 2014 were too low to estimate).

\section{Discussion}

The first companies of the greenfield CIP started operations in 2014. In 2014, off-site risk levels are so low that they cannot be estimated. By 2017, additional companies have started operations. The individual risk contours now reach the off-site areas and the societal F-N curves change from zero to the acceptable region, all indicate a clear increase of the off-site risk levels. Thus, off-site individual and societal risk levels have increased significantly from 2014 to 2017. Risk levels are still low however. The individual risk does not exceed the individual risk acceptance criteria. The societal risk falls into the acceptable region. Thus, the off-site risk levels are all deemed acceptable.

Off-site risk could become a concern in the future. A future expansion of the LPG facility with more and/or larger tanks might cause the individual risk criterion to be exceeded. If the ongoing urbanization in China leads to residential developments in the area that is now (2017) light industry, both individual and societal risk criteria may be exceeded. Because of the present location of LPG facility, it may be advisable to restrict further housing development of the off-site areas to avoid a high-density residential area. The simplified estimation procedure used in this study does not allow authoritative recommendation of this nature, a more detailed estimation is required.

We note that the greenfield CIP was laid out with no clear separation distance, or buffer zone, to off-site region. For a greenfield CIP of this magnitude $\left(19 \times 10 \mathrm{~km}^{2}\right)$, a buffer zone might have been a good idea to ensure that the long term expansion in both off-site areas and companies at this CIP can be done without compromising land-use planning risk criteria. 
Moreover based on this retrospective QRA study, it is evident that it is more economical to consider the risk at the beginning of the land-use planning both for industrial and urban development projects. The cost to reduce the risk in an initial stage of a project is low as it is still in planning phase. Thus, we recommend strengthening risk management before construction permits are issued at an early stage. We also recommend using a buffer zone to maintain reasonable separation distances when developing the new chemical industrial parks.

As regards the methodology, the proposed simplified QRA approach will overestimate the risk because of the inherent conservative assumptions used in the calculations. However, all other things equal, this approach is cost effective (with respect to time and resources needed to carry it out) and provides a quick estimate of off-site risk stemming from chemical parks. This result is valuable in itself and can be used to justify the need for a more detailed QRA study. 


\section{Conclusions}

This retrospective QRA study estimates the risk of a Chinese chemical industrial park and analyze its impact on its off-site populated areas in 2014 and 2017, respectively.

The study reviews past major accidents and concludes that the major hazards relevant to the off-site areas are accidents involving storage of LPG, gasoline, crude oil and acrylonitrile. The study applies event tree analysis to estimate off-site risk levels.

The results indicate that the individual and the societal risks of off-site areas are acceptable in 2014 and 2017, respectively. While the current risk calculation has shown that it has an acceptable level, the authorities should review carefully and monitor the risk level in case of future development activities around and within chemical industrial park. In particular, it is noted that an expansion of LPG facility in the industrial park or an increase of population density in the nearby residential areas could significantly alter the current off-site risk levels. We therefore recommend detailed quantitative analysis be conducted when operating new activities/change in the inventory in the industrial park to take precautionary action in time.

From this retrospective study, it is clear that improved safety can be achieved at little cost at the design stage for chemical industrial activities that are situated near urban areas. The QRA analysis performed considering the inventory and situation in 2014 and now in 2017 clearly indicate that any future expansion of the chemical park carefully consider risk analysis a priori before making a decision on locating a new activity/company within the park. Also in that respect, residential area expansion due to LUP risks should be carefully monitored with respect to future activities in the chemical park e.g. preserving a buffer zone is a promising idea. For future chemical park design, it is highly recommended to proactively include QRA analysis on a regular basis to account of dynamic changes within CIP and outside CIP in residential/commercial developments. 


\section{Acknowledgements}

The first author is thankful to China Scholarship Council (CSC), Ministry of Education (File No. 201606430020) for the grant of a scholarship for one year abroad. Also, the first author wishes to acknowledge the support from the Department of Chemical and Biochemical Engineering at DTU which hosted the secondment abroad and the consulting group COWI. This work has also been supported by the National Key Research and Development Program (No. 2016YFC0801501). 


\section{References}

[1] H. Pasman and G. Reniers, "Past, present and future of Quantitative Risk Assessment (QRA) and the incentive it obtained from Land-Use Planning (LUP)," J. Loss Prev. Process Ind., vol. 28, pp. 2-9, 2014.

[2] F. Khan and S. Abbasi, "Assessment of risks posed by chemical industries - application of a new computer automated tool maxcred-III," J. Loss Prev. Process Ind., vol. 12, no. 6, pp. 455-469, 1999.

[3] S. Baesi, B. Abdolhamidzadeh, C. R. C. Hassan, M. D. Hamid, and G. Reniers, "Application of a multi-plant QRA: A case study investigating the risk impact of the construction of a new plant on an existing chemical plant's risk levels," J. Loss Prev. Process Ind., vol. 26, no. 5, pp. 895-903, 2013.

[4] R. M. Darbra, J. Casal, E. Pastor, J. A. Vílchez, J. Arnaldos, and E. Planas, "Risk analysis active learning through the investigation of real cases," Process Saf. Environ. Prot., vol. 90, no. 5, pp. 430-435, 2012.

[5] Z. C. W. Miao Zhang, Wenhua Song, "Risk Assessment for Fire and Explosion Accidents of Steel Oil Tanks Using Improved AHP Based on FTA," Process Saf. Prog., vol. 35, no. 3, pp. 260-269, 2016.

[6] X. Seguí, R. M. Darbra, J. A. Vílchez, and J. Arnaldos, "Methodology for the quantification of toxic dispersions originated in warehouse fires and its application to the QRA in Catalonia (Spain)," J. Loss Prev. Process Ind., vol. 32, pp. 404-414, 2014.

[7] F. I. Khan, R. Sadiq, and T. Husain, "Risk-based process safety assessment and control measures design for offshore process facilities," J Hazard Mater, vol. 94, no. 1, pp. 1-36, 2002.

[8] Z. Tan, J. Li, Z. Wu, J. Zheng, and W. He, "An evaluation of maintenance strategy using risk based inspection," Saf. Sci., vol. 49, no. 6, pp. 852-860, 2011.

[9] V. Cozzani, R. Bandini, C. Basta, and M. D. Christou, "Application of land-use planning criteria for the control of major accident hazards: A case-study," J. Hazard. Mater., vol. 136, no. 2, pp. 170-180, 2006.

[10] P. Peng and D. Zhao, "Study on access of enterprises in chemical parks based on risk," J. Saf. Sci. Technol., vol. 4, p. 17, 2013.

[11] T. M. Liu, M. H. Zhong, and J. J. Xing, "Industrial accidents: Challenges for China's economic and social development," Saf. Sci., vol. 43, no. 8, pp. 503-522, 2005.

[12] R. J. Willey, J. Murphy, and A. Baulch, "The explosion in Tianjin, China, August 12, 2015," Process Saf. Prog., vol. 34, no. 4, p. 312, 2015. 
[13] G. Fu, J. H. Wang, and M. W. Yan, “Anatomy of Tianjin Port Fire and Explosion: Process and Causes,” Process Saf. Prog., vol. 35, no. 3, pp. 216-220, 2016.

[14] H. D. Zhang and X. P. Zheng, "Characteristics of hazardous chemical accidents in China: A statistical investigation,” J. Loss Prev. Process Ind., vol. 25, no. 4, pp. 686-693, 2012.

[15] J. Zhao, J. Suikkanen, and M. Wood, "Lessons learned for process safety management in China," J. Loss Prev. Process Ind., vol. 29, no. 1, pp. 170-176, 2014.

[16] F. P. Lees, Loss Prevention in the Process Industries. Butterworth-Heinemann, 2003.

[17] I. C. M. Pietersen, "Analysis of the LPG Incident in SAN JUAN IXHUATEPEC, Mexico City," 1985.

[18] M. Maremonti, G. Russo, E. Salzano, and V. Tufano, "Post-Accident Analysis of Vapour Cloud Explosions in Fuel Storage Areas," Process Saf. Environ. Prot., vol. 77, no. 6, pp. 360-365, 1999.

[19] Buncefield Major Incident Investigation Board, "Buncefield Major Incident Investigation," 2005.

[20] Buncefield Major Incident Investigation Board, “The Buncefield Investigation: Third Progress report," 2006.

[21] C. D. Argyropoulos, M. N. Christolis, Z. Nivolianitou, and N. C. Markatos, "A hazards assessment methodology for large liquid hydrocarbon fuel tanks," J. Loss Prev. Process Ind., vol. 25, no. 2, pp. 329-335, 2012.

[22] French Ministry of Environment, "Boilover of a crude oil tank in Milford Haven," 2008.

[23] U.S. Chemical Safety Board, "Reactive Incident Data Table, 1980 to 2001," U.S. Chemical Safety Board, 2017. .

[24] China State Administration of Work Safety, Individual and Societal Acceptable Risk Criteria of Production and Storage Facilities of Hazardous Chemicals (Decree No. 13). 2014.

[25] A. W. Evans and N. Q. Verlander, "What is wrong with criterion FN-lines for judging the tolerability of risk?," Risk Anal., vol. 17, no. 2, pp. 157-168, 1997.

[26] P. Baybutt, “The ALARP Principle in Process Safety," Process Saf. Prog., vol. 33, no. 1, pp. 36-40, 2014.

[27] Chinese National Standard, "Code of urban residential areas planning \& design (GB5018093)." 1993.

[28] Chinese National Standard, "Guideline for Quantitative Risk Assessment of Chemical Enterprises (AQ/T 3046-2013).” 2013. 
[29] Buncefield Major Incident Investigation Board, "Recommendations on land use planning and the control of societal risk around major hazard sites," 2008.

[30] Anon., "Reference Manual Bevi Risk Assessments," National Institute of Public Health and the Environment, Bilthoven, The Netherlands, 2009. 


\section{Abbreviations}
ALARP ..... As low As Reasonably Practicable
BLEVE $\quad . . . . \quad$ Boiling Liquid Expanding Vapor Explosion
CIP …. Chemical Industrial Park
LFL ..... Lower Flammable Limit
LPG ...... Liquefied Petroleum Gass
QRA …. Quantitative Risk Assessment
VCE $\quad . . . . \quad$ Vapor Cloud Explosion 